\title{
Scaling Up Patient-Centered Interdisciplinary Care for Multimorbidity: A Pragmatic Mixed- Methods Randomized Controlled Trial
}

Martin Fortin, MD, MSc

Moira Stewart, $\mathrm{PbD}$

Patrice Ngangue, MD, PbD

José Almirall, $M D, P b D$

Matbieu Bélanger, PbD

Judith Belle Brown, PbD

Martine Couture, RN, MPA

Frances Gallagher, $\mathrm{PbD}$

Alan Katz, MBCbB, MSc

Cbristine Loignon, $\mathrm{PbD}$

Bridget L. Ryan, PbD

Tara Sampalli

Sabrina T. Wong, RN, PbD

Merrick Zwarenstein, $M B B C b$, $M S c, P b D$

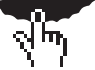

MORE ONLINE

www.annfammed.org
Conflict of interest: authors report none

\section{CORRESPONDING AUTHOR}

Martin Fortin

Department of Family Medicine and Emergency Medicine Université de Sherbrooke 3001 12e Ave N

Quebec, Canada, J1H 5N4

Martin.Fortin@usherbrooke.ca

\begin{abstract}
PURPOSE To measure the effectiveness of a 4-month interdisciplinary multifaceted intervention based on a change in care delivery for patients with multimorbidity in primary care practices.

METHODS A pragmatic randomized controlled trial with a mixed-methods design in patients aged 18 to 80 years with 3 or more chronic conditions from 7 family medicine groups (FMGs) in Quebec, Canada. Health care professionals (nurses, nutritionists, kinesiologists) from the FMGs were trained to deliver the patientcentered intervention based on a motivational approach and self-management support. Primary outcomes: self-management (Health Education Impact Questionnaire); and self-efficacy. Secondary outcomes: health status, quality of life, and health behaviors. Quantitative analyses used multi-level mixed effects and generalized linear mixed models controlling for clustering within FMGs. We also conducted in-depth interviews with patients, family members, and health care professionals.
\end{abstract}

RESULTS The trial randomized 284 patients (144 in intervention group, 140 in control group). The groups were comparable. After 4 months, the intervention showed a neutral effect for the primary outcomes. There was significant improvement in 2 health behaviors (healthy eating with odds ratios [OR] 4.36; $P=.006$, and physical activity with OR 3.43; $P=.023$ ). The descriptive qualitative evaluation revealed that the patients reinforced their self-efficacy and improved their self-management which was divergent from the quantitative results.

CONCLUSIONS Quantitatively, this intervention showed a neutral effect on the primary outcomes and substantial improvement in 2 health behaviors as secondary outcomes. Qualitatively, the intervention was evaluated as positive. The combination of qualitative and quantitative designs proved to be a good design for evaluating this complex intervention.

Ann Fam Med 2021;19:126-134. https://doi.org/10.1370/afm.2650.

\section{INTRODUCTION}

Much effort has been deployed internationally to improve care and outcomes for persons with multimorbidity in primary care. The PatientCentered Innovations for Persons with Multimorbidity research program, funded by the Canadian Institutes of Health Research, had an overall goal to build on existing structures and initiatives to evaluate patient-centered innovations relevant to multimorbidity in primary care. ${ }^{1}$ At variance with most self-management interventions focused on single diseases, this research focused on multiple morbidities experienced by patients in primary care, a priority for intervention research. ${ }^{2,3}$ As part of this program, trials were conducted in 2 Canadian provinces, Quebec and Ontario. We report the Quebec trial where the research team collaborated with a regional health care organization to implement an integrated chronic disease prevention and management program into family medicine groups (FMG), the most prevalent type of primary care practice in Quebec. ${ }^{4,5}$ 
There are 2 main conceptual models underpinning this intervention: the Chronic Care Model ${ }^{6,7}$ and the Patient-Centered Clinical Method. ${ }^{8}$ Both models have inspired interventions that improved outcomes in a variety of circumstances. ${ }^{9}$ The intervention presented here is part of a scale-up of a demonstration project (PR1MaC) which reported acceptable quantitative and qualitative effectiveness in the same geographic region in 2012..$^{10,11}$ Whereas the demonstration project used a team of trained professionals managed by the research team to deliver a patient-centered intervention within practices, ${ }^{12}$ the scaled-up intervention was delivered by professional health care professionals already in place or relocated within the FMGs. Training was provided under the control of the health care organization, which is better aligned with the existing governance structure and is more pragmatic. ${ }^{13,14}$ The objective of this trial was to assess the effectiveness of the multifaceted intervention based on a change in care delivery for patients with 3 or more chronic conditions after 4 months.

\section{METHODS}

The intervention protocol was described previously. ${ }^{12}$ We conducted a concurrent triangulation mixed methods study, with convergent quantitative and qualitative components. ${ }^{15}$ The first component was a pragmatic randomized controlled trial with a delayed intervention in the control group to evaluate the effect of the intervention on patient's self-management and self-efficacy for managing chronic diseases. The second component used a descriptive qualitative approach. Both quantitative and qualitative data were gathered concurrently, as part of the outcomes evaluation, and then synthesized in an effort to best understand the intervention's impact on patient outcomes.

\section{Setting}

All of the 11 FMGs in the Saguenay-Lac St-Jean region were invited to implement the intervention by the regional health authority. The offer included the addition of health care professionals to complete the primary care teams, adding a nutritionist and a kinesiologist, and a 2-day training for the additional staff and health care professionals already within each FMG. The research team was responsible for the training. After a formal presentation to the family doctors responsible for each FMG and to the regional family medicine governing body, they were invited to participate in the trial and 7 accepted.

\section{Recruitment}

Primary care clinicians received information, visual reminders along with posters (for the waiting room), relating to the intervention, and the process to refer the patients as part of the initial material presented to each participating FMG. Based on their clinical evaluation and judgement, they referred adult patients for the self-management support intervention relating to their chronic conditions. To be included in the trial, patients had to be aged 18 to 80 years and have 3 or more chronic conditions. They had to be cognitively intact, able to speak French, to read, and to give consent. The upper limit of patients aged 80 years for the trial was used in an effort to minimize loss to follow-up.

\section{Randomization}

Patients referred to the intervention were contacted by telephone by a research assistant before their first visit with a nurse, to assess eligibility and obtain informed consent. After consent, a baseline questionnaire including all the outcomes and the sociodemographic questions was completed for every patient. Then the research assistant opened a sealed opaque envelope containing the group allocation obtained by simple randomization and informed the patients of their group assignment (intervention or control). A contact nurse, at each FMG, was informed when it was time to start the intervention. Complete blinding and allocation concealment were not feasible in this pragmatic trial.

\section{Intervention}

The intervention is considered a change in care delivery. It encompassed 3 components: (1) training the professionals, (2) suggesting clinical pathways for patients, and (3) creating a community of practice within each FMG. Training was provided for the professionals in each participating FMG (contact nurses, other nurses, nutritionists, kinesiologists, and others if present and interested). Training focused on 4 themes: (1) patientcentered care for persons with multimorbidity, (2) self-management support, (3) interprofessional collaboration, and (4) motivational approach. Suggested clinical pathways with individual visits to health care professionals were developed for each patient. Pathways started with a contact nurse who performed a clinical assessment, elicited patients' goals, and created an individualized care plan. Patients were then referred to the most appropriate professional(s) matching patient goals, including referrals to the nurses themselves. A final visit was with the contact nurse to summarize and plan for sustainability. All of this had to be carried on with fluid communications among the clinical team.

The intervention was planned to be delivered in less than 4 months. Cumulative time spent by the professionals was expected to be less than 7 hours per patient, but it was up to the team to decide depending on patient needs and the objectives. The creation 
of a community of practice paired 1 contact nurse in each FMG with the regional manager. The role of this community of practice was to solve ongoing problems relating to the unfolding of the care pathway within each practice, to encourage interprofessional collaboration within each FMG, to ensure compliance with the ongoing research process, and to respect allocation of patients. A fidelity assessment was conducted to determine whether the clinical pathway unfolded as planned. ${ }^{16,17}$

\section{Control}

Patients assigned to the control group were placed on a waiting list to receive the intervention after 4 months. In the meantime, they had access to their usual care including elective appointments with their family doctors or urgent appointments with their heath care professionals for acute reasons (trauma, infection, etc).

\section{Outcomes}

Primary outcomes were the Health Education Impact Questionnaire (heiQ) $)^{18,19}$ and Self-Efficacy for Managing Chronic Diseases (SE-CD). ${ }^{20,21}$ We used the versions validated in French for both. ${ }^{22,23}$ With 42 questions, the heiQ encompasses 8 domains that are scored separately: health directed behavior, positive and active engagement in life, emotional well-being, self-monitoring and insight, constructive attitudes and approaches, skill and technique acquisition, social integration and support, and, finally, health service navigation. The heiQ was used in a previous study in the same region..$^{10}$ The SE-CD is a shorter questionnaire of 6 questions and has been used extensively in published research. ${ }^{21}$

Secondary outcomes included health status measured by the validated Veterans RAND 12 Item Health Survey (VR-12) (RAND Corporation), which permitted calculation of physical and mental sub-component scores. ${ }^{24}$ The VR-12 was developed from the Veterans RAND 36-Item Health Survey which was developed from the Medical Outcomes Study RAND SF-36 Version 1.0. ${ }^{24}$ Other secondary outcomes were quality of life as measured with the EuroQol 5-dimensions questionnaire, ${ }^{25,26}$ psychological distress as measured with the Kessler 6-item Psychological Distress Scale Questionnaire, ${ }^{27,28}$ and health behaviors assessed with specific questions from the Enquête de santé du Saguenay-Lac-Saint Jean 2007 and the Behavioral Risk Factor Surveillance System. ${ }^{29,30}$ Health behavior variables were dichotomized as follows: tobacco smoking (yes or no), physical activity (yes if at least 20-30 minutes 2 or more times per week, no for less activity), healthy eating (yes if good to excellent habits were self-reported, no for bad to poor habits reported). The criteria for classifying participants as having high risk alcohol consumption were the following: more than 10 standard drinks per week for women or more than 15 standard drinks per week for men, ${ }^{31}$ and/or drinking alcohol 4 or more times in a week.

The complete list of outcome measures is presented in Supplemental Table 1, available at https://www.Ann FamMed.org/content/19/2/126/suppl/DC1/, along with their psychometric properties when available. In this study, multimorbidity was defined as the presence of 3 or more chronic conditions out of a list of 20 (see Supplemental Table 2, available at https://www.Ann FamMed.org/content/19/2/126/suppl/DC1/). ${ }^{32,33}$

Concurrent with the quantitative assessment, we conducted in-depth interviews ${ }^{34,35}$ to answer the following question: how did the intervention affect patients outcomes? We used a purposive sample of 3 types of stakeholders: health care professionals representing all disciplines that delivered the intervention; patients of various age, sex, education, and location that completed the intervention; and family members of those patients. Interviewers were a mix of research professionals and coinvestigators. ${ }^{36}$ The interview guides included open-ended questions to capture participants' perceptions of the intervention. Regular debriefing was conducted among the interviewers to ensure rigor and confirm that there were no new themes emerging (indicating saturation)..$^{37,38}$

\section{Sample Size and Statistical Power}

We estimated the sample size required for the trial for the primary outcome variables with 2-sided $\alpha=0.05$ and $80 \%$ power. For continuous scores like those generated in each domain of the heiQ, we estimated that 64 patients in both the intervention group and the control group would have allowed detection of a medium effect size based on the standard deviation (0.5). ${ }^{39}$ This number was doubled to allow more flexibility in the analyses and to account for a potential cluster effect within practices. Anticipating a drop-out rate of 15 to $30 \%$, we aimed at a total sample size of 325 patients. For the qualitative sample, recruitment and data collection continued until saturation was achieved. ${ }^{37}$

\section{Data Analysis}

Comparison of the outcomes between intervention and control groups at 4 months accounted for baseline scores using multilevel modeling to account for clustering at the level of the individual (repeated measures) and at the level of the FMG. ${ }^{40}$ Multilevel modeling allows the use of partial data from subjects who did not participate in all measurements. Continuous variables were analyzed with linear mixed models and dichotomous variables were analyzed with generalized 
linear mixed models. All cases remained in their assigned groups and no imputation was performed for missing data including lost to follow-up. We also conducted intention-to-treat analyses where those lost to follow-up in either group were considered unchanged from baseline. All analyses were performed using SPSS version 21 for Windows (SPSS Inc).

All qualitative interviews were audio recorded and transcribed verbatim. Debriefing after each period of data collection was conducted with interviewers to decide when saturation was obtained. ${ }^{38} \mathrm{~A}$ thematic analysis using an iterative and interpretative approach ${ }^{41}$ was independently conducted by 2 team members to determine the key concepts emerging from the data. Consensus was reached on themes and subthemes. Exemplar quotes were identified that illustrated the themes and subthemes. The final analysis was shared with a larger group of coinvestigators. NVivo 10 software (QSR International Pty Ltd) was used to manage the qualitative data. Merging the quantitative results and the qualitative findings occurred as the last step in the analysis in order to compare and contrast the results looking for patterns or contradictions. ${ }^{42}$

\section{RESULTS}

This trial randomized a total of 284 patients, 144 in the intervention group and 140 in the control group, from July 2016 through July 2017 in 7 family medicine groups. All participants were White. Implementation and training of the health care professionals were conducted in waves to adapt to the local contexts (timing of the FMG recruitment, resource and trainer availability, geography). The complete flowchart is presented in Supplemental Figure 1, available at https://www. AnnFamMed.org/content/19/2/126/suppl/DC1/. Lost to follow-up were $16 \%$ in the control group and $12 \%$ in the intervention group. The analysis of patients' characteristics, shown in Table 1, demonstrated that the groups were comparable. The mean number of chronic conditions was 5.0 in both groups. Patient's initial assessment of the intervention demonstrated an intervention fidelity of $80.2 \%$ while interprofessional intervention fidelity was $70 \%$. These components of clinical intervention were negatively influenced by moderating factors such as context, participant responsiveness, and the intervention complexity. ${ }^{16,17}$

\section{Primary Outcomes}

Among the 8 domains of the heiQ, only 1 showed a statistically significant difference favoring the intervention group (Table 2). Specifically, the self-monitoring and insight domain demonstrated a statistically significant improvement, although the effect was relatively small. All other domains of the heiQ were scored high and remained stable over the follow-up period. The score of the SE-CD also was quite high at baseline in both groups and seemed to improve slightly in both groups, resulting in a zero-effect relating to the intervention (Table 2). Overall, the results for the primary outcomes could be considered as neutral.

\section{Secondary Outcomes}

The results for the secondary outcomes are presented in Tables 3 and 4. Among the outcomes, physical activity and healthy eating improved significantly in the intervention group as compared with the controls. Health status and quality of life did not appear to be affected by the intervention. No adverse events were reported.

Intention-to-treat analyses on both primary and secondary outcomes that implies imputation of data are presented as supplemental files (see Supplemental Tables 3-5, available at https://www. AnnFamMed.org/ content/19/2/126/suppl/DC1/) as they did not change the interpretation of results.

\section{Table 1. Control and Intervention Group Characteristics at Baseline ${ }^{\mathrm{a}}(\mathrm{N}=\mathbf{2 4 8})$}

\begin{tabular}{|c|c|c|}
\hline Characteristic & $\begin{array}{l}\text { Control } \\
(n=140)\end{array}$ & $\begin{array}{l}\text { Intervention } \\
(n=144)\end{array}$ \\
\hline Age, mean (SD), y & $61.1(10.3)$ & $60.8(10.6)$ \\
\hline $\begin{array}{l}\text { Number of chronic diseases, } \\
\text { mean (SD) }\end{array}$ & $5.0(1.7)$ & $5.0(1.9)$ \\
\hline Males, No. (\%) & $63(45.0)$ & $69(47.9)$ \\
\hline \multicolumn{3}{|l|}{ Education level, No. (\%) } \\
\hline Incomplete secondary school & $30(21.4)$ & $36(25.0)$ \\
\hline Completed secondary school & $38(27.1)$ & $30(20.8)$ \\
\hline College & $54(38.6)$ & $66(45.8)$ \\
\hline University & $18(12.9)$ & $12(8.3)$ \\
\hline \multicolumn{3}{|l|}{$\begin{array}{l}\text { Household income in CAD\$, } \\
\text { No. } \% \text { ) }\end{array}$} \\
\hline$<20,000$ & $26(18.6)$ & $26(18.1)$ \\
\hline $20,000-49,999$ & $54(38.6)$ & $52(36.1)$ \\
\hline$\geq 50,000$ & $55(39.3)$ & $59(41.0)$ \\
\hline Missing data & $5(3.6)$ & $7(4.9)$ \\
\hline \multicolumn{3}{|l|}{ Marital status, No. (\%) } \\
\hline Married & $92(65.7)$ & $92(63.9)$ \\
\hline Single or divorced & $43(30.7)$ & $43(29.9)$ \\
\hline Widower & $5(3.6)$ & $9(6.3)$ \\
\hline \multicolumn{3}{|l|}{ Employment, No. (\%) } \\
\hline Employed & $45(32.1)$ & $51(35.4)$ \\
\hline Unemployed & $26(18.6)$ & $26(18.1)$ \\
\hline Retired & $69(49.3)$ & $67(46.5)$ \\
\hline \multicolumn{3}{|l|}{ CAD $\$=$ Canadian dollars } \\
\hline \multicolumn{3}{|c|}{$\begin{array}{l}\text { Differences between both groups were not statistically different for any } \\
\text { characteristic. }\end{array}$} \\
\hline
\end{tabular}


Table 2. Results of Primary Outcomes

\begin{tabular}{|c|c|c|c|c|c|c|c|}
\hline \multirow[b]{2}{*}{ Primary Outcome } & \multicolumn{2}{|r|}{ T1 } & \multicolumn{2}{|r|}{$\mathrm{T} 2$} & \multicolumn{3}{|c|}{ Marginal Mean Differences } \\
\hline & No. & Mean (SD) & No. & Mean (SD) & $\begin{array}{l}\text { Mean } \\
\text { at T2 }\end{array}$ & $\begin{array}{c}\text { Difference I-Ca } \\
(95 \% \mathrm{Cl})\end{array}$ & $\begin{array}{c}P \\
\text { Value }^{b}\end{array}$ \\
\hline \multicolumn{8}{|l|}{ Healthdirected behavior } \\
\hline Control & 140 & $2.82(0.90)$ & 118 & $2.80(0.91)$ & 2.84 & & \\
\hline Intervention & 144 & $2.82(0.92)$ & 127 & $2.91(0.88)$ & 2.89 & $0.05(-0.12$ to 0.22$)$ & .55 \\
\hline \multicolumn{8}{|c|}{ Positive, active engagement in life } \\
\hline Control & 140 & $3.62(0.41)$ & 118 & $3.65(0.40)$ & 3.66 & & \\
\hline Intervention & 144 & $3.58(0.43)$ & 127 & $3.62(0.42)$ & 3.62 & $-0.04(-0.13$ to 0.05$)$ & .42 \\
\hline \multicolumn{8}{|l|}{ Emotional well-being } \\
\hline Control & 140 & $3.09(0.78)$ & 118 & $3.25(0.76)$ & 3.27 & & \\
\hline Intervention & 144 & $3.09(0.75)$ & 127 & $3.26(0.74)$ & 3.25 & $-0.02(-0.16$ to 0.13$)$ & .81 \\
\hline \multicolumn{8}{|c|}{ Self-monitoring and insight } \\
\hline Control & 140 & $3.51(0.37)$ & 118 & $3.39(0.42)$ & 3.39 & & \\
\hline Intervention & 144 & $3.54(0.36)$ & 127 & $3.63(0.37)$ & 3.62 & 0.23 (0.13 to 0.32$)$ & $<.01$ \\
\hline \multicolumn{8}{|c|}{ Constructive attitudes, approaches } \\
\hline Control & 140 & $3.63(0.45)$ & 118 & $3.70(0.40)$ & 3.69 & & \\
\hline Intervention & 144 & $3.58(0.51)$ & 127 & $3.65(0.51)$ & 3.66 & $-0.03(-0.12$ to 0.07$)$ & .57 \\
\hline \multicolumn{8}{|c|}{ Skill and technique acquisition } \\
\hline Control & 140 & $3.44(0.53)$ & 118 & $3.52(0.51)$ & 3.53 & & \\
\hline Intervention & 144 & $3.45(0.51)$ & 127 & $3.61(0.50)$ & 3.61 & $0.08(-0.03$ to 0.17$)$ & .17 \\
\hline \multicolumn{8}{|c|}{ Social integration and support } \\
\hline Control & 139 & $3.51(0.55)$ & 118 & $3.59(0.51)$ & 3.55 & & \\
\hline Intervention & 144 & $3.37(0.71)$ & 127 & $3.54(0.67)$ & 3.58 & $0.02(-0.08$ to 0.13$)$ & .64 \\
\hline \multicolumn{8}{|c|}{ Health service navigation } \\
\hline Control & 140 & $3.77(0.38)$ & 118 & $3.78(0.43)$ & 3.77 & & \\
\hline Intervention & 144 & $3.74(0.38)$ & 127 & $3.82(0.29)$ & 3.82 & $0.06(-0.02$ to 0.13$)$ & .16 \\
\hline \multicolumn{8}{|l|}{ Self-efficacy score } \\
\hline Control & 140 & $7.6(1.50)$ & 118 & $7.8(1.50)$ & 7.76 & & \\
\hline Intervention & 142 & $7.6(1.8)$ & 127 & $7.8(1.6)$ & 7.84 & $0.08(-0.21$ to 0.37$)$ & .58 \\
\hline
\end{tabular}

Table 3. Results of Secondary Outcomes (Continuous Variables)

\begin{tabular}{|c|c|c|c|c|c|c|c|}
\hline \multirow[b]{2}{*}{ Secondary Outcome } & \multicolumn{2}{|r|}{ T1 } & \multicolumn{2}{|r|}{ T2 } & \multicolumn{3}{|c|}{ Marginal Mean Differences } \\
\hline & No. & Mean (SD) & No. & Mean (SD) & $\begin{array}{l}\text { Mean } \\
\text { at T2 }\end{array}$ & Difference I-Ca $(95 \% \mathrm{Cl})$ & $\begin{array}{c}P \\
\text { Value }^{b}\end{array}$ \\
\hline \multicolumn{8}{|c|}{ VR-12 Physical Component Summary } \\
\hline Control & 140 & $39.5(10.5)$ & 118 & $40.9(9.3)$ & 41.25 & \multirow[t]{2}{*}{$-0.35(-2.31$ to 1.62$)$} & \multirow[t]{2}{*}{.73} \\
\hline Intervention & 144 & $40.5(11.0)$ & 127 & $41.1(10.7)$ & 40.91 & & \\
\hline \multicolumn{8}{|c|}{ VR-12 Mental Component Summary } \\
\hline Control & 140 & $54.7(9.5)$ & 118 & $54.8(9.6)$ & 54.67 & \multirow[t]{2}{*}{$0.68(-1.42$ to 2.78$)$} & \multirow[t]{2}{*}{.52} \\
\hline Intervention & 144 & $53.6(11.5)$ & 127 & $55.4(10.4)$ & 55.35 & & \\
\hline \multicolumn{8}{|l|}{ EQ-5D-5L Index } \\
\hline Control & 139 & $0.839(0.126)$ & 118 & $0.850(0.112)$ & 0.850 & \multirow[t]{2}{*}{$-0.020(-0.047$ to 0.007$)$} & \multirow[t]{2}{*}{.14} \\
\hline Intervention & 144 & $0.838(0.145)$ & 127 & $0.831(0.152)$ & 0.830 & & \\
\hline \multicolumn{8}{|c|}{$\begin{array}{l}\text { EQ-5D-5L = 5-level EuroQol 5-dimensions questionnaire; I-C = intervention minus control; } T 1=\text { baseline; } T 2=\text { study end point at } 4 \text { months; VR-12=Veterans RAND } \\
\text { 12-Item Health Survey. }\end{array}$} \\
\hline $\begin{array}{l}\text { a Difference } \mathrm{I}-\mathrm{C}=\text { marginal me } \\
\text { b Multilevel modeling (linear } n\end{array}$ & ion) & $\begin{array}{l}\text { arginal mean at } \\
\text { ults at } T 2 \text {, adju }\end{array}$ & . & 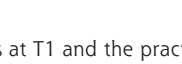 & & & \\
\hline
\end{tabular}




\section{Table 4. Results of Secondary Outcomes (Dichotomous Variables)}

\begin{tabular}{|c|c|c|c|c|}
\hline Seconday Outcome & $\begin{array}{l}\text { T1 }{ }^{\mathrm{a}} \\
\text { No. }(\%)\end{array}$ & $\begin{array}{l}\text { T2 } \\
\text { No. }(\%)\end{array}$ & OR $(95 \% \mathrm{Cl})$ & $\begin{array}{l}P \\
\text { Value }^{c}\end{array}$ \\
\hline \multicolumn{5}{|l|}{ Psychological distress (K6) } \\
\hline Control & $64(45.7)$ & $42(35.9)$ & & \\
\hline Intervention & $64(44.4)$ & 44 (34.6) & $1.08(0.57-2.03)$ & .824 \\
\hline \multicolumn{5}{|c|}{ High-risk alcohol consumption } \\
\hline Control & $12(8.6)$ & $10(8.5)$ & & \\
\hline Intervention & $7(4.9)$ & $7 / 127(5.5)$ & $1.24(0.24-6.54)$ & .798 \\
\hline \multicolumn{5}{|l|}{ Smoking habit } \\
\hline Control & $21(15.0)$ & $22(18.6)$ & & \\
\hline Intervention & $32(22.2)$ & $29(22.8)$ & $2.40(0.46-12.37)$ & .297 \\
\hline \multicolumn{5}{|l|}{ Physical activity } \\
\hline Control & $72(51.4)$ & $55(46.6)$ & & \\
\hline Intervention & $63(43.8)$ & $76(59.8)$ & $2.60(1.37-4.93)$ & .003 \\
\hline \multicolumn{5}{|l|}{ Healthy eating } \\
\hline Control & $75(53.6)$ & $70(59.3)$ & & \\
\hline Intervention & $70(48.6)$ & $92(72.4)$ & $2.42(1.30-4.50)$ & .006 \\
\hline \multicolumn{5}{|c|}{$\begin{array}{l}\text { K6 }=\text { Kessler } 6 \text {-item Psychological Distress Scale Questionnaire; OR = odds ratio; } \mathrm{T} 1 \text { = baseline; } \mathrm{T} 2=\text { study end } \\
\text { point at } 4 \text { months. }\end{array}$} \\
\hline \multicolumn{5}{|c|}{$\begin{array}{l}\text { Total size per group at T1: control } n=140 \text {, intervention } n=144 \text {. } \\
\text { b Total size per group at T2: control } n=118 \text { (except } n=117 \text { for psychological distress), intervention } n=127 \text {. } \\
\text { 'Multilevel modeling (generalized linear mixed model) comparing results at T2, adjusted for values at T1 and } \\
\text { the practice. }\end{array}$} \\
\hline
\end{tabular}

of life of as mentioned by a caregiver: "He works better, he has better health, we see him right away ... he lost 10 pounds" (family member 05).

\section{DISCUSSION}

This pragmatic trial obtained mixed results in a population of patients with multimorbidity. The trial was neutral for the primary outcomes. In comparison, the demonstration project, on which the intervention was built, succeeded in improving 6 out of 8 domains of the heiQ with a population that was a little younger (mean age of 52 years compared with a mean age of 61 years in this study) but with the same mean number of chronic conditions. ${ }^{10}$ Many elements could explain the differences between the 2 studies. In the demonstration project, the

\section{Qualitative Findings}

We recruited 30 participants for the qualitative evaluation: 9 patients, 16 health care professionals (9 nurses, 4 nutritionists, 2 kinesiologists, and 1 respiratory therapist), and 5 family members. Interviews lasted from 23 to 74 minutes (mean of 47 minutes). Complete characteristics of the participants are described elsewhere. ${ }^{43}$ Participants reported that the intervention led to an improvement in the patients' self-efficacy, self-management, health status, and quality of life. The improvements mainly concerned certain lifestyle habits such as diet and physical exercise. The coaching conducted by the different health care professionals during the intervention with the patients reinforced their self-efficacy and led to an increase in self-management behaviors and a feeling of greater control as illustrated by a patient: "The intervention has changed my life. Every day I eat fruits and vegetables, and since then, I monitor my health very well" (patient 01 ).

During the patients' follow-up, health care professionals also observed improvements with implications for patients' health status, including better control of glycemia and cholesterol, weight loss, and medication decrease: "There are many patients who have taken care of themselves and who have stopped certain medications, who have managed to control their diabetes or even their cholesterol without medication" (health care professional 13, nutritionist). Family members and patients perceived an improvement in patients' quality participants completed a self-administered questionnaire. In this study, the questionnaire was administered by a research assistant. The mean scores of the heiQ varied from 2.62 to 3.28 in the demonstration project at baseline compared with 2.82 to 3.74 in this study (maximum score is 4 ) which did not leave much space for improvement in the present study. The use of an interviewer and a desirability bias may explain in part this ceiling effect. ${ }^{43}$ Also in the demonstration project, the intervention was standardized and under the control of the research team. The pragmatic nature of the present study with the intervention delivered by the professionals from the FMGs may explain the lack of improvement. Interventions implemented in a realworld setting lead to adaptations and are influenced by contextual factors which can affect the intervention fidelity and consequently the results. ${ }^{44,45}$ Finally, as the recruitment was under the control of the primary care providers within the FMGs, some may have selected patients with lower needs for an intervention on the basis of their motivation.

As for the self-efficacy score, this study failed to improve it but, at 7.6 for a maximum of 10 , the score was already considered a high score compared with the 5.2 (SD 2.2) described by Lorig. ${ }^{21}$ A closer look at the results revealed that less than $10 \%$ of the patients had a SE-CD score of 5.2 or lower at baseline and around $40 \%$ had a score of 8 or more. Other studies have reported high scores of the SE-CD and a ceiling effect 
thus limiting improvement. ${ }^{23}$ The same phenomenon was reported in the demonstration project. ${ }^{10}$

The FMG are an improved model of Primary Care in Quebec which created/encouraged groups of family physicians with nurse support. Given that these family physicians volunteered for this new model started in 2002, they may be providing already a high quality of primary care and further improvements could be difficult to obtain.

For the secondary outcomes, this study was able to reproduce the results of the demonstration project by improving self-reported physical activity and healthy eating. ${ }^{10}$ The calculated numbers needed to treat are 9 for physical activity and 4 for healthy eating.

Among the qualitative findings, participants reported improvement in patient self-efficacy, selfmanagement behaviors, health status, and quality of life. The findings are consistent with previous studies reporting patient benefits of one-to-one contact with health care professionals in their approach to selfmanagement. ${ }^{46}$ As expressed by the patients in another qualitative study embedded in this research program, ${ }_{1}^{43}$ to obtain these benefits, interventions should be tailored to patient's needs and include combinations of strategies to improve treatment knowledge, psychological coping, stress management, and lifestyle choices. ${ }^{47}$ Noteworthy, the qualitative findings relating to the other heiQ domains as well as self-efficacy and quality of life were divergent from the quantitative results.

The modest results of this pragmatic trial are nonetheless a step in the right direction. The most recent systematic review on primary care interventions for patients with multimorbidity reported mixed outcomes and came to the conclusion that we may not yet have found the best way to intervene or to measure efficacy and effectiveness in this particular population. ${ }^{48}$ Recently, a major pragmatic cluster randomized trial conducted in the United Kingdom reported negative primary and secondary outcomes in an intervention for patients with multimorbidity. ${ }^{49}$ The intervention was patient-centered and involved the professionals collocated at the practices and the comparator was usual care. The main outcome was quality of life measured by EuroQol 5-dimensions in the absence of more specific measures for patients with multimorbidity. That study, like ours, failed at improving quality of life even with a longer duration. What lesson should we learn from those repeated neutral or mixed results trials? Particularly in this one, in light of the divergence between the qualitative and the quantitative, is it time to revisit our choice of outcomes? Part of the solution may be to have patients and clinicians engaged with the researchers from the start to determine the right outcomes or what constitutes successful outcomes.

\section{Strengths and Limitations}

The main strength of this study resides in its use of mixed methods, its randomization, and its pragmatism, particularly its implementation in a real-world environment. We used a generic person-centered intervention, and no attempt was made to focus on particular patterns of multimorbidity.

The short duration of the intervention may have limited its ability to demonstrate notable effects. Further, it is impossible to tell whether the effects noted, particularly for the secondary outcomes, will be sustained for a prolonged period. As described elsewhere, pragmatic trials are associated with substantial implementation challenges. The current study was implemented in a context of major changes in the governance of provincial and regional health care systems. At the practice level, many clinicians had to move from one practice to another and the research team had to repeat the training for new clinicians. These organizational changes may have impeded the potential to get optimal effects from the intervention and may have reduced the fidelity and the effect of the intervention. Also, given full range of scales could not be used, the choice of outcomes for this intervention may have limited the potential to document positive effects. The variety of patients with different conditions limited the use of specific or disease-oriented outcomes. Finally, the lack of outcomes developed for a population of patients with multimorbidity is also an issue to be addressed in future research. ${ }^{48}$

\section{CONCLUSION}

Quantitatively, this patient-centered interdisciplinary intervention for patients with multimorbidity showed a neutral effect for primary outcomes and substantial improvement in health behaviors as secondary outcomes. Qualitatively, the intervention was evaluated as positive by patients, health care professionals, and family members. This study informs us about challenges of implementation for this type of intervention. The combination of qualitative and quantitative methods proved to be a good design for evaluating such a complex intervention, suggesting that this type of evaluation is adequate to be used in future studies using pragmatic interventions on patients with multiple morbidities. Regarding the outcomes to be prioritized, our study informs the use of health behavior outcomes as a good choice to evaluate the effects of such an intervention.

To read or post commentaries in response to this article, go to https://www.AnnFamMed.org/content/19/2/126/tab-e-letters.

Key words: interdisciplinary research; multimorbidity; patient care team; pragmatic clinical trial 
Submitted December 20, 2019; submitted, revised, July 7, 2020; accepted July 15, 2020.

Funding support: Dr Martin Fortin holds the Research Chair on Chronic Diseases in Primary Care, Université de Sherbrooke. Dr Moira Stewart was funded by the Dr Brian W. Gilbert Canada Research Chair in Primary Health Care Research (2003-2017).

Prior presentation: Presented at the 47th NAPCRG Annual Meeting; November 16-20, 2019; Toronto, Canada.

Trial registration: ClinicalTrials.gov, no NCT02789800.

Acknowledgments: The authors want to acknowledge the other coinvestigators, staff, and international advisors of the Patient-Centered Innovations for Persons with Multimorbidity team who have contributed to make this research program a success: Bayliss EA, Berbiche $D$, Bhattacharyya $O$, Boeckxstaens $P$, Borgès Da Silva R, Bouhali $T$, Chouinard M-C, Furler J, Glazier R, Hogg W, Huras P, Little P, Maddocks H, Maltais M-E, Mercer S, Nicholson K, Paradis M, Piccinini-Vallis H, Poitras M-E, Ramond-Roquin A, Reichert $S$, Salisbury C, Sasseville M, Smith S, Sussman J, Thind A, van den Akker M, Wodchis W. We also want to acknowledge the primary care clinicians from the Saguenay-Lac St-Jean that have implemented the intervention and participated with the research team.

Supplemental materials: Available at https://www.AnnFamMed. org/content/19/2/126/suppl/DC1/.

\section{References}

1. Stewart M, Fortin M; Patient-Centred Innovations for Persons with Multimorbidity Team. Patient-Centred Innovations for Persons with Multimorbidity: funded evaluation protocol. CMAJ Open. 2017;5(2): E365-E372.

2. National Institutes of Health. Identifying innovative mechanisms or interventions that target multimorbidity and its consequences (R01 Clinical Trial Optional). Published 2020. Accessed Jun 30, 2020. https://grants.nih.gov/grants/guide/pa-files/PAR-20-180.html

3. Canadian Institutes of Health Research. CIHR Institute of Health Services and Policy Research Strategic Plan 2015-19. Published 2016. Accessed Jun 30, 2020. https://cihr-irsc.gc.ca/e/49711.html

4. Clair M. Les Solutions émergentes: rapport et recommandations. Commission d'enquête sur les services de santé et de bien-être. Ottawa: Gouvernement du Canada; 2000.

5. Breton $M$, Lévesque JF, Pineault $R$, Hogg W. Primary care reform: can quebec's family medicine group model benefit from the experience of ontario's family health teams? Healthc Policy. 2011;7(2):e122-e135.

6. Bodenheimer T, Wagner EH, Grumbach K. Improving primary care for patients with chronic illness. JAMA. 2002;288(14):1775-1779.

7. Bodenheimer T, Wagner EH, Grumbach K. Improving primary care for patients with chronic illness: the chronic care model, Part 2. JAMA. 2002;288(15):1909-1914.

8. Stewart MA, Belle Brown JB, Weston WW, McWhinney IR, McWilliam CL, Freeman TR. Patient-Centered Medicine: Transforming the Clinical Method. 3e ed. Cornwall: Radcliffe Medical Press Ltd; 2015.

9. Poitras ME, Maltais ME, Bestard-Denommé L, Stewart M, Fortin M. What are the effective elements in patient-centered and multimorbidity care? A scoping review. BMC Health Serv Res. 2018;18(1):446.

10. Fortin M, Chouinard M-C, Dubois M-F, et al. Integration of chronic disease prevention and management services into primary care: a pragmatic randomized controlled trial (PR1MaC). CMAJ Open. 2016;4(4):E588-E598.

11. Fortin M, Chouinard MC, Diallo BB, Bouhali T. Integration of chronic disease prevention and management services into primary care (PR1MaC): findings from an embedded qualitative study. BMC Fam Pract. 2019;20(1):7.

12. Fortin M, Chouinard MC, Bouhali T, Dubois MF, Gagnon C, Bélanger $\mathrm{M}$. Evaluating the integration of chronic disease prevention and management services into primary health care. BMC Health Serv Res. 2013;13:132.
13. Loudon K, Treweek S, Sullivan F, Donnan P, Thorpe KE, Zwarenstein M. The PRECIS-2 tool: designing trials that are fit for purpose. BMJ. 2015;350:h2147.

14. Zwarenstein M, Treweek S, Gagnier JJ, et al; CONSORT group; Pragmatic Trials in Healthcare (Practihc) group. Improving the reporting of pragmatic trials: an extension of the CONSORT statement. BMJ. 2008;337:a2390.

15. Creswell JW. Research Design: Qualitative, Quantitative and Mixed Methods Approaches. 2nd ed. Thousand Oaks: Sage Publications Inc; 2003.

16. Carroll C, Patterson M, Wood S, Booth A, Rick J, Balain S. A conceptual framework for implementation fidelity. Implement Sci. 2007;2:40.

17. Hasson H. Systematic evaluation of implementation fidelity of complex interventions in health and social care. Implement Sci. 2010;5:67.

18. Nolte S, Elsworth GR, Sinclair AJ, Osborne RH. The extent and breadth of benefits from participating in chronic disease selfmanagement courses: a national patient-reported outcomes survey. Patient Educ Couns. 2007;65(3):351-360.

19. Osborne RH, Elsworth GR, Whitfield K. The Health Education Impact Questionnaire (heiQ): an outcomes and evaluation measure for patient education and self-management interventions for people with chronic conditions. Patient Educ Couns. 2007;66(2):192-201.

20. Sherer M, Maddux JE, Mercandante B, Prentice-Dunn S, Jacobs B, Rogers RW. The self-efficacy scale: construction and validation. Psychol Rep. 1982;51(2):663-671.

21. Lorig KR, Sobel DS, Ritter PL, Laurent D, Hobbs M. Effect of a selfmanagement program on patients with chronic disease. Eff Clin Pract. 2001;4(6):256-262.

22. Bélanger $A$, Hudon C, Fortin M, Amirall J, Bouhali T, Chouinard $M-C$. Validation of a French-language version of the health education impact Questionnaire (heiQ) among chronic disease patients seen in primary care: a cross-sectional study. Health Qual Life Outcomes. 2015;13:64.

23. Hudon C, Chouinard MC, Bélanger A, et al. The Self-Efficacy for Managing Chronic Disease Scale - French version: A validation study in primary care. Eur J Pers Cent Healthc. 2014;2(4):533-538.

24. Kazis LE, Selim A, Rogers W, Ren XS, Lee A, Miller DR. Dissemination of methods and results from the veterans health study: final comments and implications for future monitoring strategies within and outside the veterans healthcare system. J Ambul Care Manage. 2006;29(4):310-319.

25. EuroQol Group. EuroQol-a new facility for the measurement of health-related quality of life. Health Policy. 1990;16(3):199-208.

26. Xie F, Pullenayegum E, Gaebel K, et al; Canadian EQ-5D-5L Valuation Study Group. A time trade-off-derived value set of the EQ5D-5L for Canada. Med Care. 2016;54(1):98-105.

27. Kessler RC, Barker PR, Colpe LJ, et al. Screening for serious mental illness in the general population. Arch Gen Psychiatry. 2003;60(2): 184-189.

28. Safran MA, Strine TW, Dhingra SS, Berry JT, Manderscheid R, Mokdad AH. Psychological distress and mental health treatment among persons with and without active duty military experience, Behavioral Risk Factor Surveillance System, United States, 2007. Int J Public Health. 2009;54(Suppl 1):61-67.

29. Centers for Disease Control and Prevention (CDC). Behavioral Risk Factor Surveillance System Survey Questionnaire. Atlanta, Georgia: U.S. Department of Health and Human Services, Centers for Disease Control and Prevention; 2007.

30. Bergeron A, Clouston M-C, Couture R, Duplain M, Lapierre R, Therrien G. Enquête de santé du Saguenay-Lac-Saint Jean. 2007 - Rapport sommaire. Direction de santé publique, Agence de la santé et des services sociaux du Saguenay-Lac-Saint-Jean https://www.santesaglac. gouv.qc.ca/medias/medias_et_documentation/Portraits_de_la_ population/Enquetes_de_sante/ENQ_REG_SANTE_RAPP_SOMM_ 2007.pdf

31. Butt P, Beirness D, Gliksman L, Paradis C, Stockwell T. Alcohol and health in Canada: A summary of evidence and guidelines for low risk drinking. Published 2011. Accessed Nov 17, 2013. https://www. uvic.ca/research/centres/cisur/assets/docs/report-alcohol-and-healthin-canada.pdf 
32. Fortin M, Stewart M, Poitras ME, Almirall J, Maddocks H. A systematic review of prevalence studies on multimorbidity: toward a more uniform methodology. Ann Fam Med. 2012;10(2):142-151.

33. Fortin M, Almirall J, Nicholson K. Development of a research tool to document self-reported chronic conditions in primary care. J Comorb. 2017;7(1):117-123.

34. Sandelowski M. Combining qualitative and quantitative sampling, data collection, and analysis techniques in mixed-method studies. Res Nurs Health. 2000;23(3):246-255.

35. Thorne S. Interpretative Description: Qualitative Research for Applied Research. 2nd ed. Routledge; 2016.

36. Sandelowski M. Whatever happened to qualitative description? Res Nurs Health. 2000;23(4):334-340.

37. Saunders B, Sim J, Kingstone $T$, et al. Saturation in qualitative research: exploring its conceptualization and operationalization. Qual Quant. 2018;52:1893-907.

38. Kuzel AJ. Sampling in qualitative inquiry. In: Crabtree BF, Miller WL, eds. Doing Qualitative Research. 2nd ed. Thousand Oaks, CA: Sage Publications; 1999

39. Cohen J. Statistical Power Analysis for the Behavioural Sciences. 2nd ed. Illsdale, NJ: Academic Press; 1988.

40. Goldstein H, Browne W, Rasbash J. Multilevel modelling of medical data. Stat Med. 2002;21(21):3291-3315.

41. Patton MQ. Qualitative Research \& Evaluation Methods. 3rd ed. Thousand Oaks, CA: Sage Publication; 2002.
42. Fetters MD, Curry LA, Creswell JW. Achieving integration in mixed methods designs-principles and practices. Health Serv Res. 2013; 48(6 Pt 2):2134-2156.

43. Ngangue PA, Forgues C, Nguyen T, et al. Patients, caregivers and health-care professionals' experience with an interdisciplinary intervention for people with multimorbidity in primary care: a qualitative study. Health Expect. 2020;23(2):318-327.

44. Marsiglia FF, Booth JM. Cultural adaptation of interventions in real practice settings. Res Soc Work Pract. 2015;25(4):423-432.

45. Escoffery C, et al. A systematic review of adaptations of evidencebased public health interventions globally. Implementation Science. 2018;13:, 2018. 13(1):125-125.

46. Barlow J, Wright C, Sheasby J, Turner A, Hainsworth J. Self-management approaches for people with chronic conditions: a review. Patient Educ Couns. 2002;48(2):177-187.

47. Dineen-Griffin S, Garcia-Cardenas V, Williams K, Benrimoj SI. Helping patients help themselves: a systematic review of self-management support strategies in primary health care practice. PLoS One. 2019;14(8):e0220116.

48. Smith SM, Wallace $E_{1} \mathrm{O}^{\prime}$ Dowd T, Fortin M. Interventions for improving outcomes in patients with multimorbidity in primary care and community settings. Cochrane Database Syst Rev (2):CD003638. 2016; 3:CD006560.

49. Salisbury C, Man MS, Bower $P$, et al. Management of multimorbidity using a patient-centred care model: a pragmatic cluster-randomised trial of the 3D approach. Lancet. 2018;392(10141):41-50.

\section{CHANGE-OF-ADDRESS FORM

Please complete this form and mail to the following address or fax to Annals Circulation at 913-906-6080:

Annals of Family Medicine, Circulation Department, 11400 Tomahawk Creek Pkwy, Leawood, KS 66211-2680

Check if member of sponsoring organization: $\square$ AAFP $\square$ ABFM $\square$ STFM $\square$ ADFM

\section{$\square$ AFMRD $\square$ NAPCRG $\square$ CFPC}

ID number from label on your journal cover

OLD Information (Please print.)

Name

Company (if applicable)

Address (Street plus Apt or Ste)

\begin{tabular}{ll}
\hline City & State \\
\hline Country & Postal Code (9-digit ZIP for US) \\
\hline Telephone & Fax \\
\hline E-Mail & \\
\hline
\end{tabular}

NEW Information (Please print.)

\begin{tabular}{ll}
\hline Name \\
\hline Company (if applicable) \\
\hline Address (Street plus Apt or Ste) & \\
\hline City & Postal Code (9-digit ZIP for US) \\
\hline Country & Fax \\
\hline Telephone & \\
\hline E-Mail
\end{tabular}

